institution. As laboratories cannot be brought to patients, patients must sometimes be brought to laboratories. On balance this seems to be a situation where this applies.I am, etc.,

$$
\begin{aligned}
& \text { University of Aberdeen, } \\
& \text { Aberdeen. }
\end{aligned}
$$$$
\text { Aberdeen. }
$$

\section{Using Computers}

SIR,-The paper by Mr. S. P. Watts and Dr. E. D. Acheson (25 November, p. 476) calls for two comments. Their study is not essentially a computer method in the accepted sense of the term. It has been done manually. It could certainly be done with business machines. Of course, it is easier with a computer. Hospital activity analysis can provide "treatments" or "persons." It is a matter of input organization (an identity-fix in particular) and programming. There is no "error" between one and the other. They are different things. For year-to-year comparisons "treatments" may be a sufficient indicator. For true morbidity measurements "persons" are inadequate, since they form only the hospital tip of the iceberg.

But, as in all statistics, it depends on what you want to use the rates for. If it is for hospital management-for example, the efficient use of resources-then the "spell" is the right unit. If for disease managementfor example, for diagnosis symptom matrices -then the individual "person" record updated with the whole medical history (inside or outside the hospital)-that is, a fullblooded community health record systemis needed.

Hospital activity analysis is intended to lead into this, ${ }^{\prime}$ and some experiments are already being made to extend hospital activity analysis in this direction. In the long run the unified record will pay bigger dividends than record linkage.-I am, etc.,

$$
\begin{aligned}
& \text { BERNARD BENJAMIN, } \\
& \text { Director, } \\
& \text { Research and Intelligence Unit, } \\
& \text { Greater London Council. }
\end{aligned}
$$

London S.E.1.

\section{REFBRENCB} - Benjamin, B., Proc. roy. Soc. Med., 1967, 60,
809 .

$\checkmark$

\section{Animal Reservoirs of Salmonellae}

SIR,-I read with interest Dr. L. T. Newman's letter (4 November, p. 296) on the dangers of salmonella infections from pet tortoises and Dr. W. H. Parry's (25 November, p. 486) on the similar dangers from a pet terrapin. I am glad they have stressed the very real risks of animal reservoirs of intestinal infection which so often go unrecognized. Salmonella infections are far from rare ${ }^{1}$ and thousands of new cases occur each year in Britain. In 1965 there were 832 cases of paratyphoid fever alone in England and Wales. The paratyphoid fevers may not always cause gastrointestinal symptoms and the carrier state is common and difficult to eradicate. ${ }^{2}$ In addition to the typhoid and paratyphoid fevers salmonella infections may be far from minor illnesses," and a single outbreak in Sweden of Salmonella typhimurium was reported which caused 7,717 cases with 90 deaths.

Certain preserved foods are universally recognized as potential sources of salmonella infections. It is not so well known that nearly every animal in the world, both wild and tame, may carry salmonellae in its gastrointestinal tract, including dogs, foxes, horses, cattle, swine, sheep, goats, hedgehogs, pigeons, and even the ticks, lice, and fleas that feed on infected swine and other animals. Even the lion is not exempt, ${ }^{3}$ though it could hardly be classified as a pet except perhaps in Ethiopia.

Pet tortoises are a real hazard, but reported infections in iguanas, snakes, and lizards ${ }^{6}$ are more academic than real. As the festive season approaches, however, it is a salutary thought to remember that domestic poultry constitutes the largest single reservoir in nature and that turkeys are especially affected. Some $41 \%$ of turkeys in California were found infected with salmonellae.' The canary may be affected ${ }^{3}$ and the dog is a frequent host. In 100 dogs examined in the U.S.A. 18 were found to have salmonella infections, most of which were pathogenic for man. In Norway an infected dog was found to be responsible for six cases of paratyphoid in human beings. ${ }^{10}$ In Florida greyhounds were routinely tested, and between $32 \%$ and $55 \%$ of all dogs were found to be carriers of salmonellae. ${ }^{11}$ Dogs, after swine, were found to be the most important asymptomatic carriers and $40 \%$ of cases were due to $S$ typhimurium. Dogs and cats have been found to be responsible for $S$. choleraesuis transmission to children, ${ }^{12}$ and $13.2 \%$ of healthy dogs in the U.S.A. were found infected with salmonellae and over $1 \%$ of cats in England.'

Obviously many salmonellae in animals are non-pathogenic for man. A number may be, however, and the possibility of an enteriti being spread by a pet should always be borne in mind, especially in young children with an undiagnosed gastroenteric infection.-I am, etc.

\section{Makerere University College, \\ Kampala, Uganda.}

\section{R. L. HUCRSTEP.}

\section{REFERENCES}

1 Godber, G. E., Annual Report, Ministry of 2 Huckstep, R. L., Curr. Med. Drugs, 1965, 5, No. 6. P. 19 . tions, 1962 . Edinburgh.

- Lundbeck. H., Plazikowski, U., and Silverstolpe,

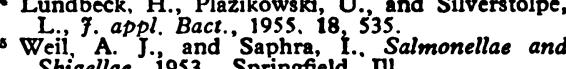
- Shigellae, igs3. Springfield, Mi.

Hinshaw, W. R., and McNeil, B., Y. Bact. (Baltimore), 1947, 53, 715.

- Fey, H. in The World Problem of Salmonellosis. edited by $\mathrm{E}_{\mathrm{B}} \mathrm{L}$. van Oye. 1964 . The Hague. Williams, J. E. in Diseases of Poultry. 1959. 4th Schwarte. Iowa.

Wolf, A. H., Henderson, $N . D_{\text {., }}$ and McCallum, G. L., Amer. A. Publ. Hlth. ig48. 38,403 1937, 10 J. A., Pork. norske. med. Selsk., Stucker, C. L., Galton. M. M., Cowdery, J., and Hardy. A. W., Y. infect. Dis., 1952, 91, 6.
Bruner, D W., and Moran, A. B., Cornell Vet. 1949, 39, 53 .

\section{Improving the Psychiatric Services}

SIR,-There is a great deal of evidence indicating that readmission rates for discharged ex-psychiatric hospital patients are less among those provided with reasonably effective psychiatric aftercare. ${ }^{-4}$

Psychiatric patients can cause great disturbance and trial to others when left at home. Visiting can provide early warning that modification of treatment or persuasion to take tablets has become urgent. Thus in quite a number of these patients a relapse can be averted. I find that a large number stop taking their tablets, and that a recurrence of symptoms within a few weeks follows. When there is no follow-up the patient will of ten not visit a doctor. Relatives are diffident about complaining. Maintenance of morale in many depressive patients does also appear to depend to some extent upon follow-up, and there being somebody, perhaps outside the immediate circle of the patient, giving disinterested help and caring. Dudgeon $^{5}$ noted that as many as $23 \%$ of 471 patients seen a year after leaving mental hospitals had had no contact with a doctor or any other type of trained mental health worker since discharge.

The consequences of a significant number of schizophrenic patients stopping tablets have been outlined. ${ }^{1-4}$ I have seen not one but a number of patients descend to further suicidal attempts following sudden cessation of antidepressant drugs. If in addition to cessation of drugs they are discharged from psychiatric outpatient clinics then it would seem vital that they be visited by someone from the mental welfare services.

In 1952 Dr. Arthur Pool initiated a six-week-in, six-week-out geriatric service in Oldham, with an associated day hospital. This alleviated the situation and did relieve many people with elderly relations as well as the patients. Spread of this system would appear to be well worth while and within the scope of numbers of existing institutions and staffs. As part of this scheme all relatives undertook to have their patients home at the end of the period so that everyone could benefit. They were made to realize that the scheme could only work widely if this was kept to. There was free use of admissions of the elderly, so that the relations who were doing their bit by keeping them at home could get off for needed holidays. Keystones in this system were the co-operation of geriatricians and of the ambulance department, which we had.-I am, etc.,

Colchester

HARRY JACOBS.

Essex.

REFERENCES

Sheldon, A., Brit. F. Psychiat., 1964, 110, 662

${ }_{3}^{2}$ Engelhardt, D. M. Rosen, B., Freedman N., ind Margolis, R., Arch. Gen. Psychiat., 1967, 16,

Pasamanick, B., Scarpitti, F. R., Lefton, M.
Dinitz, S., Wernert, J. J., and McPheeters, H., Dinitz, S., med. Ass., $1964,187,177$

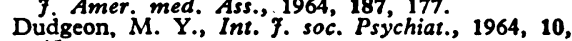
45.

\section{Intussusception Due to Hamartoma}

SIR,-A rare lesion of the base of the appendix may have initiated acute appendicitis and subsequent intussusception of the caecum, and is reported below:

A diagnosis of acute appendicitis was made on a 10-year-old boy, and at operation an acutely inflamed appendix was removed and the stump buried with a purse-string suture. Apart from oedema and local fibrinous exudate over the ileocaecal region no other abnormality was noted. The histology of the excised appendix showed acute appendicitis. After operation he made rapid progress, but on the sixth day complained of colicky abdominal pain. There was some tenderness elicited over the site of the scar, but the symptoms rapidly subsided and he was discharged home on the ninth day,

Two weeks later the patient complained of several brief attacks of colicky central abdominal pain, and during one of these his general prac- 
titioner palpated an epigastric mass. On admission the child appeared well. He was afebrile and the pulse rate was normal. The abdomen was soft and the presence of a mass was not confirmed. Rectal examination was negative, and plain $x$-rays of the abdomen showed no evidence of tluid levels or dilated loops of bowel. He was therefore observed for 24 hours, after which time he complained of further abdominal pain. Examination during a spasm of pain confirmed the presence of a tender sausage-shaped mass in the epigastrium. A diagnosis of intussusception was made, and an immediate barium enema performed, which confirmed this. The apex lay in the epigastrium. This was readily reduced by the pressure from the enema, and filling was obtained to the caecum. No barium entered the terminal ileum, and a filling defect was demonstrated in the ileocaecal region (Fig. 1). It was not possible to be certain, therefore, that reduction had been complete.

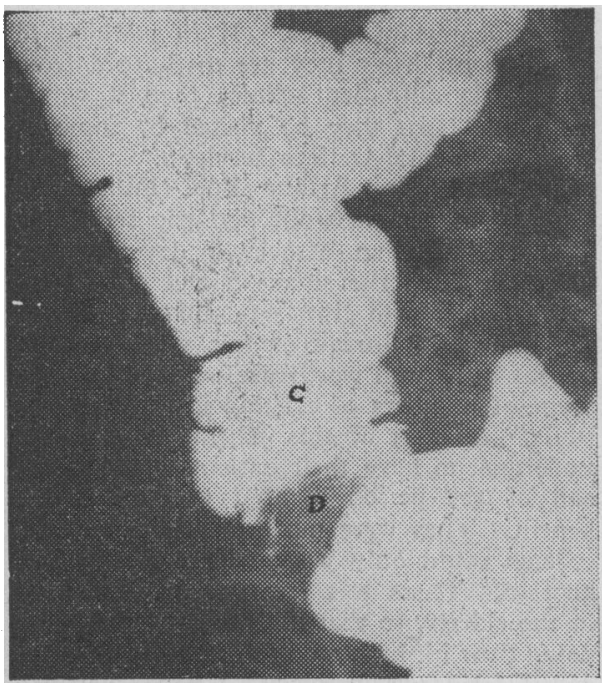

FIG. 1.-Radiograph showing the caecum (C) with a persistent filling defect (D) at its base.

Laparotomy was undertaken through a right paramedian incision under general anaesthesia. It was found that the intussusception had been completely reduced, but there was a soft mass palpable through the wall of the caecum in the region of the healed appendix stump. This felt like a tumour of approximately $3 \mathrm{~cm}$. in diameter and accounted for the filling defect seen in the radiograph and under the image intensifier. It was considered unwise to open the caecum, so a right hemicolectomy was performed and an endto-side anastomosis made between the terminal

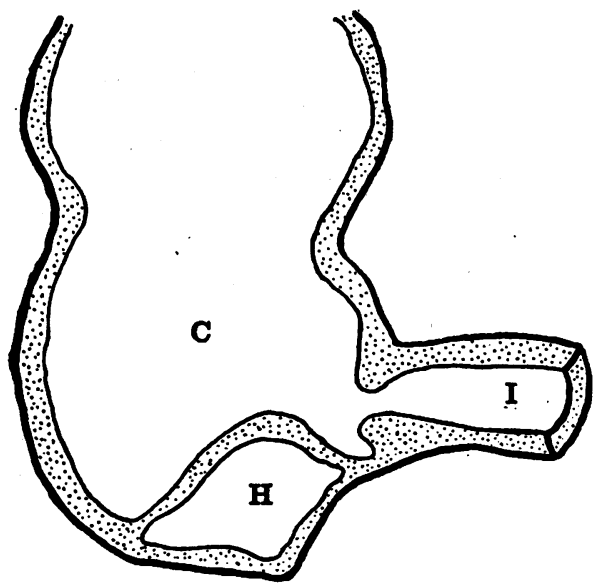

FIG. 2.-Diagram to show the position of the submucusal humartoma $(H)$ in the region of the appendix stump. I=terminal ileum. $\quad C=$ caecum. ileum and colon. The abdomen was closed and the patient made an uninterrupted recovery. He was discharged home 12 days later, and has since remained well with a single bowel action daily.

The operation specimen was opened to reveal a small intramural tumour at the site of the appendix stump (Fig. 2). This was of soft rubbery consistence and measured $3 \mathrm{~cm}$. by $2 \mathrm{~cm}$. Histologically it was shown to be a benign hamartoma showing proliferation of vascular and nervous elements.

It is possible that in this patient obstruc tion of the appendiceal lumen by the hamartoma preceded the primary infection. The apex of an intussusception may be formed by the base of the appendix where this is unduly broad, or concretions, worms, a mucocele, or a polyp protrude from the lumen.

Although it is standard practice to bury the stump the chances of this acting as the apex of an intussusception are infinitesimal. In this case the hamartoma was missed at the first operation on account of the oedema caused by the inflammatory condition, and it is suggested that burying the stump had the effect of pushing the tumour towards the lumen of the caecum, which was unduly mobile. This created the apex of the intussusception. This complication is so rare that it should not prevent the surgeon burying the appendix stump routinely.

I wish to thank Mr. D. B. Craig for permission to publish this case, Dr. J. M. Burbury for the radiograph.

-I am, etc.,

Edgware General Hospital

David P. Goodwin.

Edgware, Middx.

\section{Prevention of Rh-haemolytic Disease}

SIR,-Professor C. A. Clarke's answer (25 November, p. 484) necessitates further comment. He states that the number of cases in the various trials has increased considerably since his lecture. I have received the up-todate figures, and although the total number of cases in the United States group has increased-for example, the controls from 347 to 503-surprisingly the number of immunizations has decreased from 40 to 36 . The Liverpool and Edinburgh figures have not changed, but the German figures have actually decreased from 152 to 117 , yet show one more immunization in the controls. Difficulties of this sort had made me confine my questions to the Liverpool series.

Regarding second pregnancies, as the initiative lies with the patient to notify when pregnant again one can guess that the response has been far from complete, and it could be that abortions would less likely be reported. An individual follow-up would give more true assessment.

Professor Clarke agrees that enhancement of immunization by IgM has not been satisfactorily explained and that it is not yet known whether suppression of D-immunization is specific. The mechanism of suppression with the use of gammaglobulin is equally ill-understood and much of the current literature on immunology ${ }^{1}$ emphasizes this. As for the antigenicity of gammaglobulin, it may not be valid to compare the use of anti-D gammaglobulin in parturient normal women with gammaglobulin given to patients durng pregnancy, when there is a raised threshold to primary immunization," or with gammaglobulin given to patients suffering from agammaglobulinaemia, who have a subnormal antibody response.

Gm antigens are transfused when whole blood or plasma is given and can stimulate anti-Gm, but when the gammaglobulin is fractionated, given intramuscularly, and without the competitive red cell antigens, its antigenicity may well be enhanced. ${ }^{3}$ Frequency of stimulation is probably important, and the incidence of antiGin may be greater if gammaglobulin is given to patients who have been previously transfused. Six per cent. of Professor Clarke's treated cases have developed anti-Gm antibodies, which warrants consideration of possible clinical reactions due to these in any further transfusion of these patients, and warrants also consideration of their implication in any further pregnancies and in possible long-term effects. The hypothetical causal relationship between anti-Gm and rheumatoid arthritis has been postulated by Fudenberg and Martensson, and in fact was mentioned by Professor Clarke himself, ${ }^{s}$ and although there is probably not a simple relationship the role of anti-Gm in rheumatoid arthritis and other immunological disorders is still much under discussion. Anti-Gm antibodies often display iso-specificity and can occur in the 7S globulin. One assumes that such antibodies could cross the placenta and therefore may have an adverse effect on the foetus. Indeed, the possibility that iuvenile rheumatoid arthritis might have some such materno-foetal immunological relationship has, also been raised by Fudenberg.

Finally, differing $\mathrm{Gm}$ factors in different ethnic groups could also have some relevance when bleeding donors as a source of anti-D gammaglobulin. In view of these and other reservations I think there are " several " most important points requiring research, and that the challenge is

"How covert matters may be best disclos'd,

And open perils surest answered." fulius Caesar, Act IV, Sc. 1.

-I am, etc.,

Sheilagh MURRAY,

National Blood Transfusion Service, Newcastle upon Tyne. Region 1.

REFBRENCES

Sims, $\mathbf{F} \mathrm{H}$, and Freeman, J. W., Immunology, 1966, 11, 175 . Pollack, W.. Singher, H. O., German, J. G. and
Freda. $V$ J.. Amer. Ass. of Blood Banks Meetinx, Octoher 1967. New York.

Stirhm, E R and Fudenberg, H. H., Pediatrics, 1965, 35. 229.

Pudenberg, $H$, and Martensson, L., Bull. rheum. Dis., 1963, is, 313 .

- Clarke C A. Brit. Y. Haemat. 1967, 13, 799. N.Y Acad. Sci., 1965, 124, 884.

\section{Intrauterine Transfusion in Rh-isoimmunization}

SIR,-The paper by Professor D. V. I. Fairweather and others on intrauterine transfusion in Rh-isoimmunization (28 October, $\mathrm{p}$. 189) calls for some comment. They state that the prolonged anaemia often seen in these babies is due to the depression of bone marrow consequent on the intrauterine transfusion.

However, our personal experience suggests that this might not be the only reason. We have seen three cases of prolonged anaemia occurring in habies who had had intrauterine transfusion, who at 2 months of age had a low reticulocyte count in the peripheral blood, while the hone marrow showed clear signs of erythroid hyperplasia. Coombs test in one 